\title{
Potential Hollowfiber Polyurethane-Collagen of Chitosan Coatings As a Nerve Graft for the Therapy of Peripheral Nerve Injuries in Limb Paralysis
}

\author{
Hendita Nur Maulida ${ }^{1, *}$, Azizah Fresia Rosdiani1 ${ }^{1}$, Fitriyatul Qulub ${ }^{1}$, Disca Sandyakala \\ Purnama $^{1}$ Karina Dwi Saraswati ${ }^{1}$, Prihartini Widiyanti ${ }^{2,3}$
}

\author{
${ }^{1}$ Biomedical Engineering Study Program, Faculty of Science and Technology, Universitas \\ Airlangga, Surabaya Indonesia \\ ${ }^{2}$ Department of Physics, Faculty of Science and Technology, Universitas Airlangga, Surabaya, \\ Indonesia \\ ${ }^{3}$ Institute of Tropical Disease, Universitas Airlangga, Surabaya, Indonesia \\ *Corresponding author: henditamaulida@gmail.com
}

\begin{abstract}
Peripheral nerve injury with a gap of 5-30 mm can cause permanent paralysis because it causes an axon to break up. The distance between axons of more than $1-2 \mathrm{~cm}$ requires a graft in the form of a nerve connector to fix it. Synthesis of chitosan coated polyurethane-collagen hollowfiber has been carried out as an accelerator for healing peripheral nerve injury. The results of Fourier Transform Infra Red (FTIR) analysis showed a cross link between chitosan and glutaraldehyde seen in the shift of wave numbers from 1080$1100 \mathrm{~cm}^{-1}$ to $1002 \mathrm{~cm}^{-1}$. The degradation test results showed that the sample experienced a decrease in mass after being immersed in Simulated Body Fluid (SBF) for 7 days. Polyurethane can be degraded in the body after 30 days. This is in accordance with the mechanism of the nerve which regenerates $1 \mathrm{~mm}$ per day or 1 inch per month. Scanning Electron Microscope (SEM) analysis showed that the diameter of the hollowfiber was 2.021-2.032 mm which corresponds to the peripheral nerve diameter of 1.5-3 $\mathrm{mm}$ and the pore size of the wall is $31.33-39.65 \mu \mathrm{m}$. The results of this study are expected to provide the theoretical basis for the use of chitosan polyurethane-collagen coating composites as nerve grafts for the treatment of peripheral nerve injuries that have biocompatible properties, can regenerate and are easily degraded and provide alternative solutions for nerve graft needs that are more economical and easier to manufacture so widely produced in Indonesia.
\end{abstract}

Keywords: peripheral nerve injury, hollowfiber, polyurethane, collagen, chitosan, nerve graft.

\section{INTRODUCTION}

Peripheral nerve injury with a gap of about 5-30 $\mathrm{mm}$ both due to direct injury (87\%) and a doctor's misdiagnosis (12\%) gets special attention because it can result in permanent paralysis or disability. The Central Bureau of Statistics stated that in Indonesia as many as 
69,260 cases of accidents occurred in 2009 and 66,488 cases occurred in 2010 with most cases occurring in the extremities. Accidents like this then cause injury, the most common of which is injury in the peripheral nerve. Peripheral nerve injury can be caused by traffic accidents, work accidents, complications of surgery or sharp objects that can trigger motoric and sensory paralysis which disrupts a person's ability to move normally (Uzun et. Al., 2006).

The injured peripheral nerve has a distinctive neuronal and axonal response. The severity of the injury partially determines the degree of axonal regeneration. Although the axonal growth rate and the maturation of motor functions are slow, the rate of regeneration can be estimated. Nerve regeneration runs $1 \mathrm{~mm}$ per day or 1 inch per month. Simple peripheral nerve damage still has the potential to regenerate. However, severe peripheral nerve damage causes the axon to break up so that a nerve gap or gap occurs. About $5 \%$ of all cases of peripheral nerve damage have gaps in the nerve axons (Ijkema et. Al., 2004). The distance between the two axons of more than $1-2 \mathrm{~cm}$ requires a graft in the form of a nerve connector to fix it (Deumens, 2010).

Until now, the autologous nerve grafting or nerve autograft is known as the gold standard for handling repair of lesions in peripheral nerves over a wide range. The nerve segment is taken from other parts of the body and inserted into the lesion to provide endoneurial tubes for regenerating axons. However, this method is not a perfect therapy because of the frequent results that appear only on the return of limited functions. The limited function that can be performed by autograft directs the researcher to focus on creating a bioartificial nerve guidance conduit that uses a lot of chitosan-based material. Cui et. al. (2009) have succeeded in combining double-layer nerve conduits using polyurethane in the outer layer and collagen in the inner layer with the technique of double-nozzle lowtemperature deposition manufacturing (DLDM). Schwann cells from the nerves of mice cultured in a polyurethane-collagen composite conduit for one week experienced a significant increase in retention and survival when compared to those made from pure polyurethane and thus have a large potential for clinical use of peripheral nerve repair.

Based on this background, in this study an accelerator for the healing of peripheral nerve injury from a composite material of polyurethane (PU) was made to make collagen coated with chitosan. Polyurethane is chosen because the degradation process can be flexible. In order for nerve cells to regenerate, the selected material must not be permanent and must be degradable so that there is no need to have surgery again after the nerve regeneration process is complete to take the remaining polymer. Based on research by Cui et. al. (2009), polyurethane matrices tend to be mechanically stable if they interact with in vivo conditions while collagen fillers will improve the biological properties of the material because they promote Schwann cell adhesion, migration and proliferation. Next, the purpose of coating with 
chitosan is the biocompatible nature of chitosan because of its resemblance to the extracellular matrix of the body and its crucial role as antimicrobial. In addition, in vitro studies showed the suitability of chitosan membranes as a substrate for survival and oriented to Schwann cell growth (Yuan, 2004) and the survival and differentiation of nerve cells (Freier, 2005 and Simoes, 2011). Before coating is done, chitosan

\section{METHODS}

\section{Synthesis of Hollowfiber Polyurethane- Collagen Coating Chitosan}

Hollowfiber polyurethane is made using spinneret by dissolving $5 \%(\mathrm{w} / \mathrm{v})$ of polyurethane in chloroform and toluene. Collagen $2 \%(\mathrm{w} / \mathrm{v})$ in citric acid was loaded into a polyurethane tube, freeze at $5^{\circ} \mathrm{C}$ for 24 hours and dried for 2 hours. As a coating, chitosan was dissolved according to variations in composition $(1 \%, 1.5 \%$ and $2 \%)$ $(\mathrm{w} / \mathrm{v})$ in a $1 \%$ acetic acid solution and crosslinked with glutaraldehyde $0.5 \%$. samples were dried at $60^{\circ} \mathrm{C}$ for 2 hours and characterized.

\section{Functional Group Analysis using Fourier Transform Infra Red}

Fourier Transform Infra Red (FTIR) is used to analyze functional groups of materials and the possibility of forming new bonds. Sample using $\mathrm{KBr}$ powder as the background. The results is wave number absorption $\left(\mathrm{cm}^{-1}\right)$ to percentage of transmittance (\%) graphics.

\section{Degradation Test with Simulated Body Fluid}

will be crossed with glutaraldehyde to improve its mechanical properties. Glutaraldehyde is very reactive to amine groups in chitosan so that when reacted it will form a bridge that connects chitosan polymers to one another (Kohlpaintner et. Al., 2005). Characterization in this study included functional group analysis, material bioactivity test, and morphological test.

The degradation test was used to determine the ability of bioactivity of materials using simulation of body fluids, namely Simulated Body Fluid (SBF). The method for making SBF solution is according to Kokubo. The sample was measured for mass and soaked in $\mathrm{SBF}$ solution in a $5 \mathrm{ml}$ pot bottle. During immersion, the SBF solution in the pot bottle is changed once every 24 hours to adjust the condition of the liquid in the body. The sample is measured mass every 24 hours to determine the ability of the material to degrade in units of time. After 7 days, the mass of the remaining composite was measured and presented in graphical form of mass change over time.

\section{Morphology Test with Scanning Electron Microscope}

Scanning electron microscope (SEM) was used to determine the size and diameter of the sample. Before testing, samples are first cleaned and dried and then placed in stake holders who have been coated with gold carbon tip. Samples were analyzed in sizes below $200 \mathrm{~nm}$ 
and the output was in the form of images or images in the tiff image format.

\section{RESULTS AND DISCUSSION}

\section{Results of Function Cluster Analysis with Fourier Transform Infra Red (FTIR)}

FTIR results show absorption band at wave number $3650-3850 \mathrm{~cm}^{-1}$ which is $\mathrm{OH}$ bending vibration, wave number $3567 \mathrm{~cm}^{-1}$ which is secondary $\mathrm{NH}$ stretching vibration, wave number $3088 \mathrm{~cm}^{-1}$ which is a bending vibration of amide group $\left(\mathrm{R}^{\prime} \mathrm{NH}_{2}\right)$ as a typical group owned by collagen, wave number $1730 \mathrm{~cm}^{-1}$ which is a vibration of the urethane group (-NHCOO-), wave number $1487 \mathrm{~cm}^{-1}$ which is a bending vibration of $\mathrm{CH}_{2}$ as a typical group owned by chitosan and wave number $1002 \mathrm{~cm}^{-1}$ which is stretching vibration of chitosan $\mathrm{C}-\mathrm{O}-\mathrm{C}$ which experiences a shift in wave number from 1080$1100 \mathrm{~cm}^{-1}$ due to cross linking with $\mathrm{OH}$ groups from glutaraldehyde. The best synthesis results obtained on chitosan coating $2 \%(\mathrm{w} / \mathrm{v})$ in terms of its functional group.

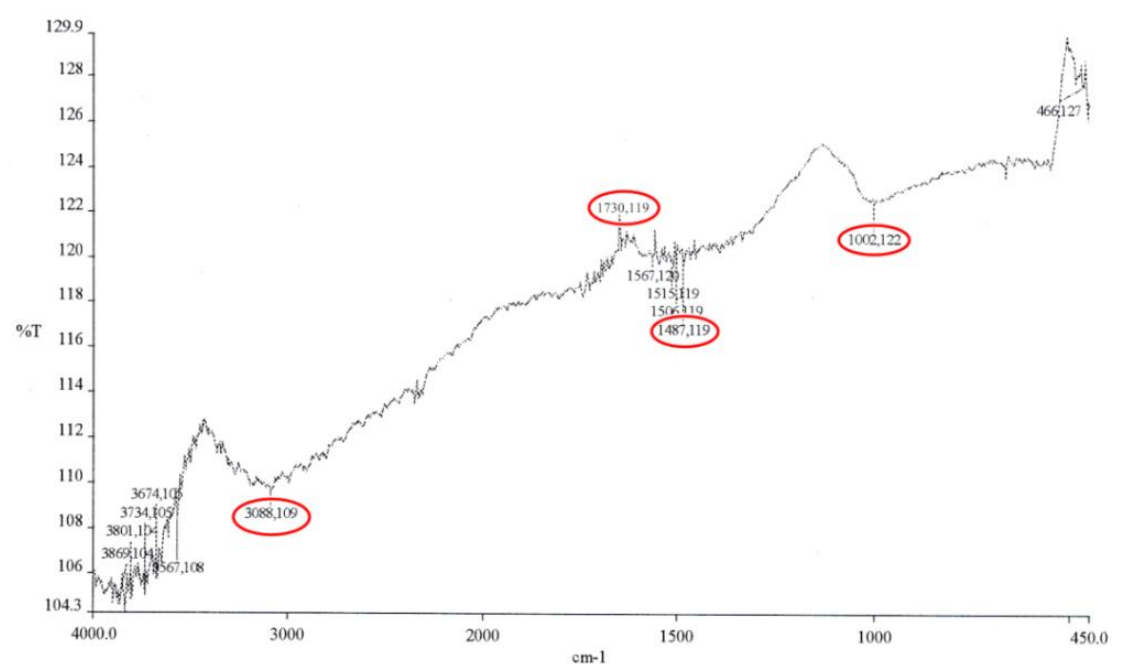

Figure 1. FTIR Spectrum of PU-Collagen-Chitosan Samples 2\% (w/v)

\section{Degradation Test Results with Simulated Body Fluid (SBF)}

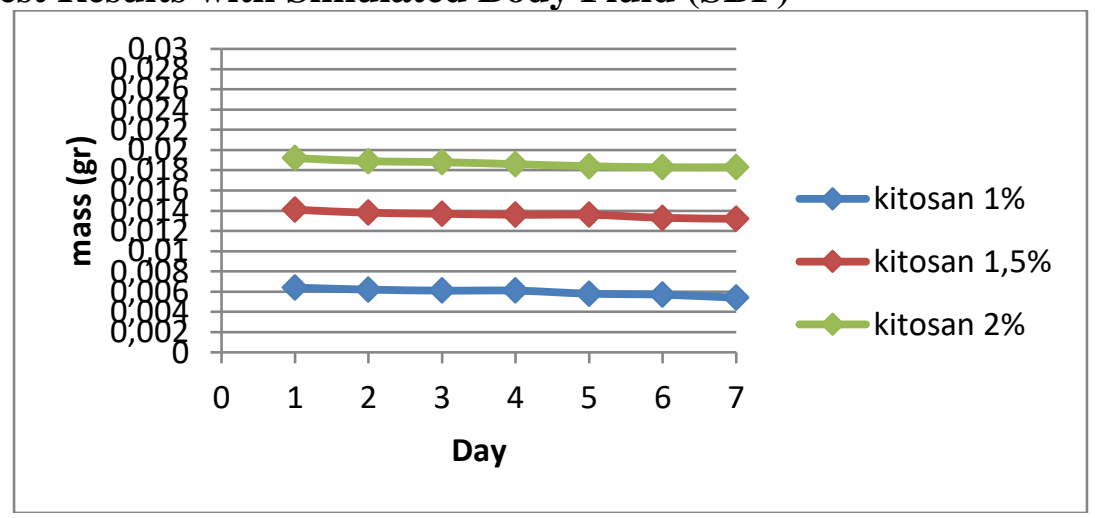

Figure 2. Graph of Mass Changes to Time 
Based on research by Rohaeti, et. al. (2004), polyurethane can be degraded in the body after 30 days. This is in accordance with the mechanism of nerves that regenerate $1 \mathrm{~mm}$ per day or 1 inch per month (Ijkema et. Al., 2004) so

\section{Morphological Test Results with Scanning Electron Microscope (SEM)}

Vertical SEM analysis of hollowfiber samples showed the distribution of values at diameter sizes of 2.021 to $2.032 \mathrm{~mm}$ and the pore size on the walls ranged from 31.33 to $39.65 \mu \mathrm{m}$ (Figure 3). This shows that the sample can be used as a healing accelerator for peripheral nerve that it can be said that polyurethane-collagen hollowfiber coated with chitosan has the potential as an accelerator for healing of biodegradable peripheral nerves.

injury. According to Pateman et. al. (2015), peripheral nerves have a diameter of $1.5-3 \mathrm{~mm}$. Meanwhile, the pores found on hollowfiber walls will make it easier for micro-sized nerve cell fibers to pass through the tube without colliding with each other so that the performance of the peripheral nerves in regenerating will be maximal.
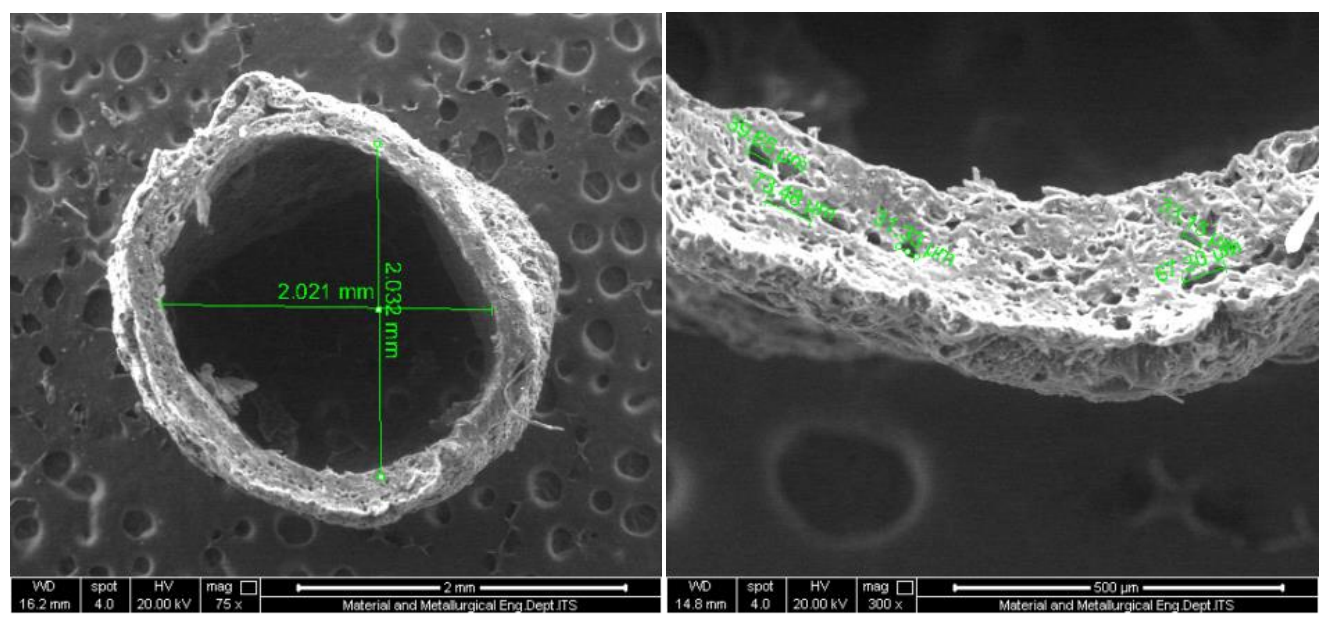

Figure 3. Horizontal PU-Collagen-Chitosan Hollowfiber Results Horizontally at 75x and 300x Magnifications Showing Diameter and Pore Size

\section{CONCLUSION}

1. Synthesis of hollowfiber PU-collagenchitosan is carried out by dissolving polyurethane $5 \% \mathrm{w} / \mathrm{v}$ into chloroform and toluene and mixed with collagen solution $2 \%$ w/v for subsequent hollowfiber use using spinneret and coated with chitosan.

2. FTIR test results show a cross link between chitosan and glutaraldehyde seen in the shift of wave numbers from $1080-1100 \mathrm{~cm}^{-1}$ to $1002 \mathrm{~cm}^{-1}$. The SBF test results show 
degraded samples which are characterized by a decrease in mass when measured in 7 days. SEM analysis showed that the hollowfiber

\section{REFERENCES}

Cui Tongkui, et. al. 2009. Rapid Prototyping a Double-layer Polyurethane--collagen Conduit and its Schwann Cell Compatibility. Journal of Bioactive \& Compatible Polymers. Di Lullo, Gloria A, Sweeney. 2002. Mapping the Ligand-binding Sites and Disease-associated Mutations on the Most Abundant Protein in the Human, Type I Collagen. J. Biol. Chem. 277 (6): 4223-4231.

Deumens R, et. al. 2010. Repairing injured peripheral nerves: Bridging the Gap. 92(3):245-76.

Freier T, et. al. 2005. Controlling cell adhesion and degradation of chitosanfilms by $\mathrm{N}$ acetylation. Biomaterials. 26:5872e8.

Ijkema, Jos-Paassen. 2005. Long-term Reinnervation Effect After Sciatic Nerve Lession in Adult Rat. Volume 187, Issue 2. Pp 113-120.

Kohlpaintner C., et. al. 2005. Aldehydes, Aliphatic, Ullmann's Encyclopedia of Industrial Chemistry, Weinheim: Wiley$\mathrm{VCH}$.

Kojio Ken, et. al. 2010. Control of Mechanical Properties of Thermoplastic Polyurethane diameter size was 2.021-2.032 $\mathrm{mm}$ and the pore size of the wall was $31.33-39.65 \mu \mathrm{m}$ so that it had the potential to be a nerve graft.

Elastomers by Restriction of Crystallization of Soft Segment. Japan: Nagasaki University.

Rohaeti Eli, et. al. 2001. Pengaruh Maltosa Terhadap Pembentukan Poliuretan. Bandung: Institut Teknologi Bandung.

Pateman Christopher, et. al. 2015. Nerve guides manufactured from photocurable polymers to aid peripheral nerve repair. UK: University of Sheffield. ELSEVIER Biomaterials 49 (2015) 77e89.

Satyanegara. 2010. Ilmu Bedah Saraf. Jakarta: Gramedia Pustaka Utama.

Sloane, Ethel. 2003. Anatomi dan Fisiologi untuk Pemula. Jakarta: EGC.

Spielmann H, et. al. 2007. The practical application of three validated in vitro embryotoxicity tests. ATLA, 527-538.

Syaifuddin, AMK. Anatomi dan Fisiologi untuk Mahasiswa Keperawatan. 2006. Jakarta: EGC.

Uzun G, Yildiz S. 2006. The role of radiology in dive-related disorders. PMID: 16532864.

Yuan Y, et. al. 2004. The interaction of Schwann cells with chitosan membranes andfibers in vitro. Biomaterials 25:4273e8.

Yurnaliza. 2002. Senyawa Khitin dan Kajian Aktivitas Enzim Mikrobial Pendegradasinya. Medan: Universitas Sumatera Utara. 